\title{
COMBUSTION CHARACTERISTICS OF IMPROVED BIODIESEL IN DIFFUSION BURNER
}

\author{
P. Kumaran, M. Gopinathan and S. Kantharrajan \\ Department of Mechanical Engineering, University Tenaga Nasional \\ 43009 Kajang, Selangor, Malaysia \\ Phone: +603-8921-2020; Fax: +603-8921-2116 \\ Email: kumaran@uniten.edu.my
}

\begin{abstract}
Biodiesel is considered as an alternative fuel for gas turbine application; however, the properties of biodiesel need further improvement in order to meet the combustion dynamics of a typical gas turbine. Therefore, this work has addressed an alternative and inexpensive method of performing combustion studies of such improved biodiesel. A diffusion burner which has similar combustion dynamics to a gas turbine combustor has been used to evaluate the combustion characteristics of improved biodiesel or Second Generation Biodiesel (SGB). The combustion characteristics of the improved biodiesel have been evaluated in terms of fuel burning rate, flame length and emissions. Subsequently, the results were compared with unimproved biodiesel or First Generation Biodiesel (FGB) and distillate diesel (DD). The results indicated improvement in physical properties; SGB and its blends possess better combustion characteristics in terms of flame length, mass of fuel flow rate and emissions compared to FGB and DD. Improvements in physical properties such as viscosity and density cause SGB fuel to possess better capillary flow than FGB. Additionally, lower carbon monoxide (CO) emissions indicate that SGB has more complete combustion than FGB. On other hand, SGB with higher saturation compounds has produced higher thermal energy with lower nitrogen oxides $\left(\mathrm{NO}_{\mathrm{x}}\right)$ compared to FGB. Thus, SGB can be considered as an alternative fuel for use in gas turbines and a 50\% blend of SGB with DD has shown promising results compared to other blend ratios.
\end{abstract}

Keywords: Gas turbine; microgasturbine; diffusion combustion; first generation biodiesel; second generation biodiesel.

\section{INTRODUCTION}

Depletion of fossil fuel resources and massive environmental destruction has intensified the need to look for alternative renewable sources such as biomass, wind, solar, hydro and biofuel. Among others, biodiesel is a clean-burning renewable fuel that is derived from vegetable oils, animal fats and waste materials. It has potential to replace fossil diesel for diesel engine applications and meets international standards, namely ASTM D6751 and EN14214. Furthermore, recent research has shown that biodiesel can even be considered for gas turbine applications, but only limited works have been reported for such applications [1]. Among the concerns are that the utilization of biodiesel may lead to high maintenance costs or cause wear that eventually reduces the efficiency of the turbine during extended operation. The metallic alkali catalyst carry over during the biodiesel production process, such as sodium and potassium, can cause turbine hot path 
corrosion and formation of deposits. These can plug off cooling holes within the turbine walls and cause erosion [2]. Moreover, the presence of phosphorus in biodiesel remains the major issue as regards the quality of the fuel in order to guarantee long-term reliability for the machine [3]. In addition, the inherited properties of biodiesel such as viscosity, density and surface tension are another impeding factor that needs to be addressed prior to gas turbine application. All these properties play an important role in the atomization process and are purely influenced by the fatty acids composition (FAMEs) of the biodiesel $[4,5]$. Thus, a research has been carried out to improve the physical properties of biodiesel (FGB) via a post-treatment scheme. Consequently, the improved fuel (SGB) has better physical properties [6], and the atomization characteristic has been also reported to have improved significantly compared to FGB [7]. Although, property improvements have been made, a preliminary combustion investigation is highly crucial to evaluate any possible impacts on the gas turbine $[1,8]$. The objective of this paper is to evaluate the combustion characteristics of SGB using a diffusion burner which is a simplified replication of the combustion dynamics of a gas turbine combustor. The combustion characteristics of SGB and its blends with DD have been evaluated in terms of flame length, mass of fuel flow rate and emissions, and subsequently the results were compared with FGB and DD.

\section{MATERIAL AND METHODS}

\section{Fuel Preparation and Property Evaluation}

Pre-treated waste cooking oil (WCO) is transesterified with methanol in the presence of sodium hydroxide to produce FGB. The methanol to molar ratio is $6: 1$ while the catalyst used is $1.0 \%$ wt of the oil. Subsequently, to react the mixture for approximately 45 minutes and allow separation of the biodiesel and glycerin by-product, washing is done to the biodiesel to remove impurities and excess methanol from the FGB. A $1000 \mathrm{ml}$ of FGB is transferred into a distillation flask and distilled at the selected temperature to produce SGB. A fractional column is then used to selectively fractionate the vapour that formed and condensed during distillation. The distillate sample is collected in a receiving flask for property evaluation at a SAMM-accredited fuel testing laboratory at TNB Research (TNBR), and gas chromatography was performed to identify the fatty acid composition of the biodiesel at the gas chromatography laboratory in University Tenaga Nasional (UNITEN). Finally, the fuel blending process was done based on volume percentage. For example, in order to produce 5 litres of fuel with blends of 5\% $\mathrm{SGB}, 250 \mathrm{ml}$ of SGB and 4,750 $\mathrm{ml}$ of distillate diesel will be prepared. The fuel mixture is heated up to $60{ }^{\circ} \mathrm{C}$ to ensure homogeneous mixing prior to combustion. The fuel preparation method is repeated for all other blends.

\section{Equipment and Material Set-up}

A simple kerosene wick burner was modified to investigate the combustion characteristics of the SGB and its blends with DD. The set-up consists of a kerosene burner, continuous emission monitoring system, glass chamber, weighing balance, metal ruler and temperature probe. The kerosene wick burner was used because it replicates and represents similar combustion dynamics to a gas turbine combustor. The combustion occurs in diffusion mode, where the fuel and air flow separately prior to combustion and are mixed at the tip of the wick. Subsequent to the diffusion flame, the 
post flame to complete the combustion is the rendering of additional secondary air that flows into the combustion zone through multiple small $1.2 \mathrm{~mm}$ orifices along two concentrically placed cylinders between the wicks. The cylinders with multiple orifices are a replication of the combustion liner in a typical gas turbine combustion chamber. Consequently, the secondary air completely oxidizes the fuel and a blue flame will exit at the end of the cylinder of the burner. A glass chamber placed at the top of the burner exit ensures the flame is steady during combustion and allows the emission to travel through along the glass chamber to be extracted by the vacuum pump via Teflon tubing that is attached with a pot on the glass chamber. A Siemens Ultramat 23 gas analyser was used to measure the emission gases such as carbon monoxide $(\mathrm{CO})$, nitrogen oxides $\left(\mathrm{NO}_{\mathrm{x}}\right)$, carbon dioxide $\left(\mathrm{CO}_{2}\right)$, and oxygen $\left(\mathrm{O}_{2}\right)$, while measurement of sulphur oxides $\left(\mathrm{SO}_{2}\right)$ was neglected since the biodiesel did not contain sulphur. In addition, a K-type temperature probe integrated with a thermometer (Fluke 54 II series with accuracy $\pm 0.05 \%$ ) was used to measure the flame temperature. Meanwhile, the fuel consumption rate was measured using a digital balance (AND; Model GF6000) and recorded in a computer via an RS232 interface. The fuel flow rate is maintained at the same level throughout the experiment. The flame length was viewed using an infrared thermal camera (FLIR ThermaCam P60) and the flame length was measured manually with the aid of a metal ruler attached to the glass chamber. Similar wicks were used for the entire experiment (length $15 \mathrm{~cm}$, width $2.5 \mathrm{~cm}$ ) and were replaced when the different types of fuel were tested. Figure 1 depicts the complete set-up of the diffusion combustion burner.

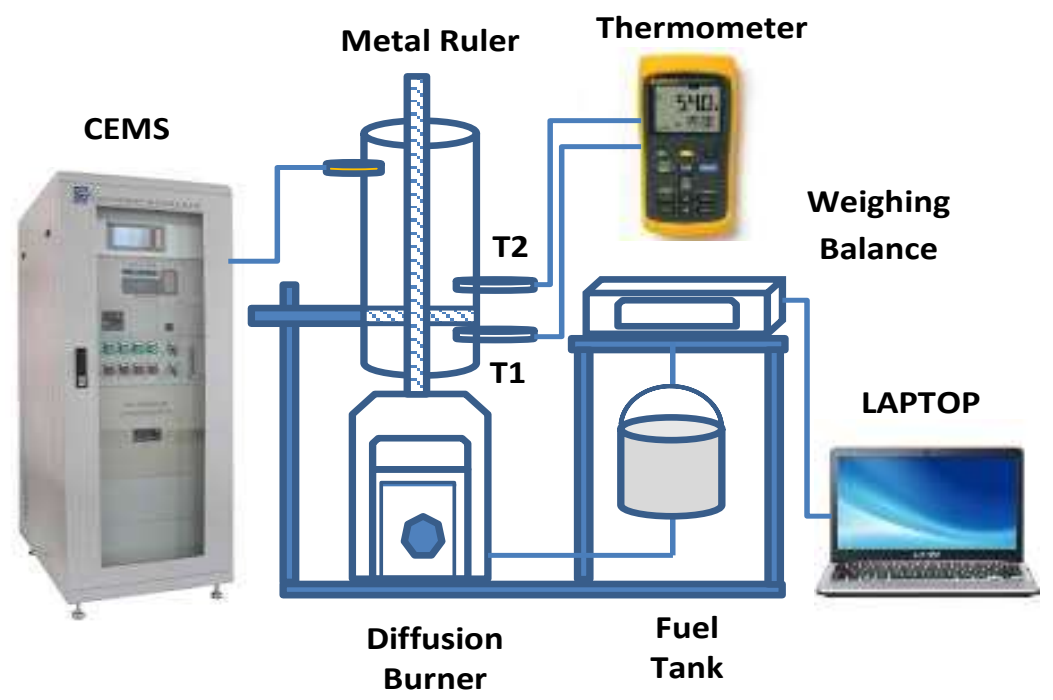

Figure 1. Complete apparatus set-up with diffusion burner.

\section{Combustion Efficacy Analysis}

Combustion efficacy was calculated to determine the heat loss due to incomplete combustion based on CO concentration. The term 'efficacy' is used instead of efficiency because only heat loss due to incomplete combustion was considered while other losses were neglected. The standard combustion analysis, Eq. (1),was simplified accordingly to calculate combustion efficacy based on $\mathrm{CO}$ emission as other losses are more appropriate for boiler plant applications $[9,10]$. Emission of $\mathrm{CO}$ obtained through 
a continuous emission monitoring system (CEMS) was used to obtain the combustion efficacy of the fuel. Emission of $\mathrm{CO}_{2}$ is an indication of complete combustion, while emission of $\mathrm{CO}$ is defined as incomplete combustion. Therefore, this simple approach was adapted for this work to evaluate the combustion efficacy of each fuel according to the details of Eq. (2) given below.

$$
\eta_{\text {efficiency }}=100-L_{1}-L_{2}-L_{3}-L_{4}-L_{5}
$$

where $\mathrm{L}_{1}=$ Heat loss due to dry flue gas

$\mathrm{L}_{2}=$ Heat loss due to evaporation of water formed due to hydrogen in fuel

$\mathrm{L}_{3}=$ Evaporation due to moisture present in fuel

$\mathrm{L}_{4}=$ Heat loss due to incomplete combustion

$\mathrm{L}_{5}=$ Heat loss due to radiation and convection

Hence, Eq. (1) was simplified as Eq. (2) to calculate combustion efficacy

$$
\eta_{\epsilon}=100-L_{4}
$$

where $\mathrm{L}_{4}=$ Heat loss due to incomplete combustion

$\mathrm{L}_{4}=\mathrm{M}_{\mathrm{CO}} \times 24010$

$\mathrm{M}_{\mathrm{CO}}=\mathrm{CO}(\mathrm{ppm}) \times \mathrm{M}_{\mathrm{f}} \times 28$

$\mathrm{M}_{\mathrm{f}}$ is the mass of fuel $(\mathrm{kg} / \mathrm{hr})$

24010 is the heat loss due to partial combustion of carbon in $\mathrm{kJ} / \mathrm{kg}$

Table 1. Physical properties of fuel.

\begin{tabular}{lcccc}
\hline \multicolumn{1}{c}{ Properties of Fuel } & Unit & DD & FGB 100 & SGB100 \\
\hline Kinematic Viscosity & $\mathrm{mm}^{2} / \mathrm{s}$ & 3.9 & 6.6 & 4.6 \\
Surface tension & $\mathrm{mN} / \mathrm{m}$ & 23 & 31 & 30 \\
Density & $\mathrm{g} / \mathrm{cm}^{3}$ & 0.845 & 0.8776 & 0.8756 \\
Calorific Value & $\mathrm{kJ} / \mathrm{kg}$ & 44800 & 38200 & 39196 \\
Saturated Compounds & $\%$ & - & 42.64 & 58.77 \\
Unsaturated Compounds & $\%$ & - & 57.36 & 41.23 \\
\hline
\end{tabular}

\section{RESULTS AND DISCUSSION}

\section{Fuel Property Analysis}

The property results of three different fuels, SGB, FGB and distillate diesel, are presented in Table 1. The result shows the improved physical properties of SGB in terms of viscosity, surface tension and density. The improvement process has successfully altered the FAMEs composition of biodiesel from more unsaturated to saturated compounds and the physical properties of the biodiesel are strongly influenced by the origin of fatty acids composition. The most significant improvement was obtained for the kinematic viscosity of SGB. Besides that, the calorific value of SGB improved by $2.61 \%$ more than FGB. Thus, SGB is expected to have higher thermal efficiency than FGB during gas turbine operation. 


\section{Mass of Fuel Flow Rate}

The mass flow rate of all the fuels is presented in Figure 2. DD serves as the benchmark for the other fuels because distilled diesel is the most common fuel used for gas turbine applications. Apparently, as the percentage of biodiesel increased in DD, the mass flow of SGB and FGB decreased. However, SGB and its blends have a higher flow rate than FGB. This is because of the distinct capillary flow rate due to the lower density and viscosity of SGB in comparison to FGB. As consequence, more SGB is absorbed by the wick during combustion compared to FGB. This result is in good agreement with [11], who conducted a flame temperature analysis of biodiesel. Nevertheless, as the percentage of SGB increased in the DD, eventually the flow rate decreased as well. It is notable that, compared to fossil diesel, biodiesel consists of long carbon chain molecules. This characteristic resists the flow of biodiesel during combustion and this is noticeable when biodiesel becomes the predominant component in the mixture. Overall, SGB and its blends have a higher flow rate than FGB and are comparable to DD up to $50 \%$ blend of SGB.

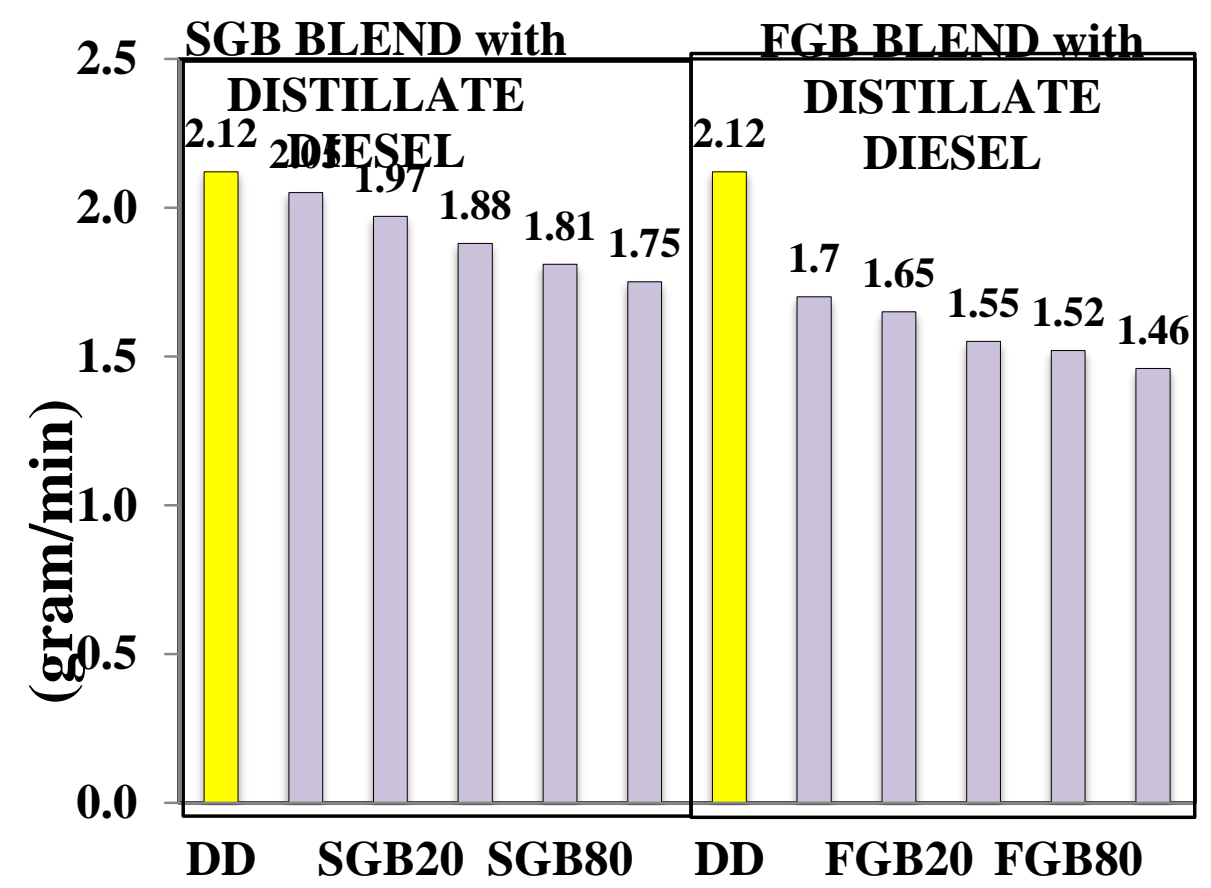

Figure 2. Mass flow rate of different types of fuel.

\section{Flame Length}

Flame length is an important parameter that needs consideration prior to gas turbine application. The longer post flame in combustion chamber will cause detrimental effects to turbine parts. This current work has deployed infrared thermal imager to view the flame and manually measured the length of each fuel. The results are presented in Figure 3. SGB50 has recorded highest flame length and SGB20 has similar flame length as DD. However, the pattern is similar for both SGB and FGB where as the blend percentage increases the flame length become shorter except for SGB50. The similar results reported by Tan (2008), where DD recorded as the longest flame and followed by FGB20, FGB50, FGB80 and FGB100. On the other hand, SGB100 has longer and 
stable flame compare to FGB100. This may be associated with burning rate of the fuel because improvement in physical properties caused SGB posses better capillary flow than FGB. Thus, more SGB absorbed and burnt consistently during combustion than FGB. Correspondingly, the thermal images in Figure 4 prove that, the flame of SGB100 more stable and longer than FGB100. In addition, the formation of yellow smoke is lower for SGB which is an indication of complete combustion compared to FGB100. This is because soot formation decreased when the level of unsaturated fatty acid decreased in the fuel composition [11]. In terms of flame length, SGB20 is proved to be suitable to replace distillate diesel. Meanwhile, further investigation is recommended for SGB 50 because it may not be suitable for microgasturbine due to longer flame and limitation in combustor design; however can consider for gas turbine application because gas turbine has bigger combustor than microgasturbine.

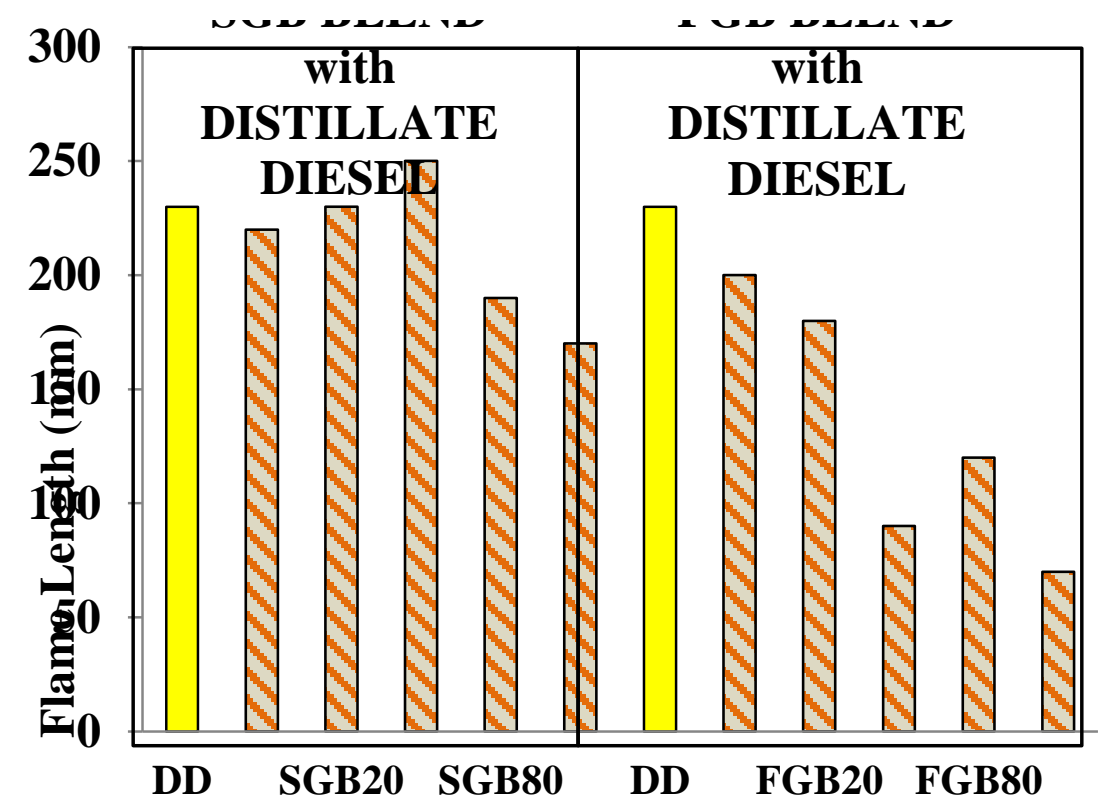

Figure 3. Flame length versus fuel sample.

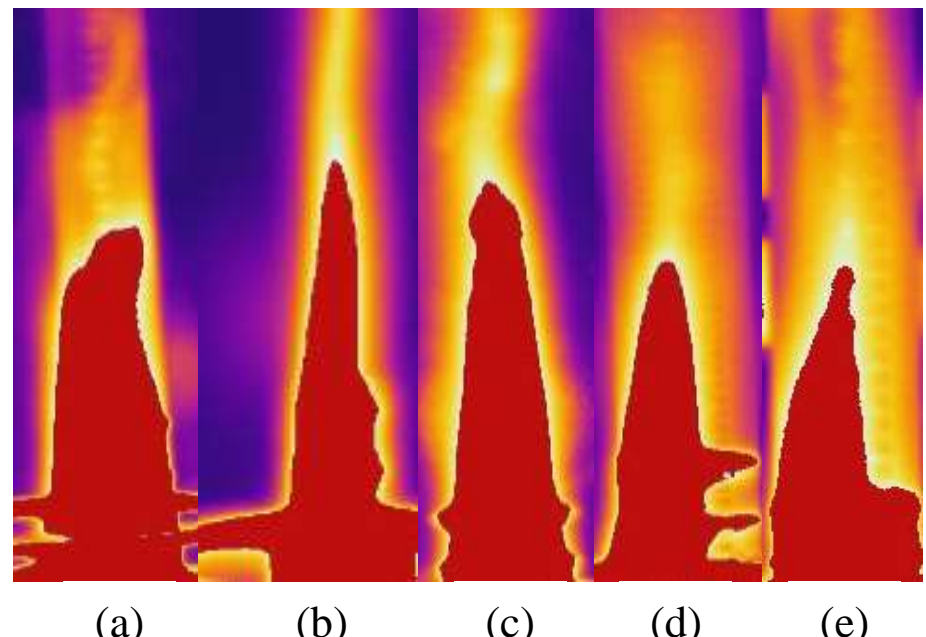

Figure 4. Thermal images for different fuels:

(a) distillate diesel; (b) SGB50; (c) SGB100; (d) FGB50; (e) FGB100. 


\section{Emission and Combustion Efficacy}

A continuous emission monitoring system was used to measure the emission gases during combustion and the results are presented in Figures 5,6 and 7. The system was calibrated using calibration gases prior to measurement. Based on the results in Figure 5, emission of CO decreased significantly as the percentage of SGB increased in the DD. On the contrary, emission of $\mathrm{CO}$ increased when the percentage of FGB increased in the DD. Apparently, the results show an inverse relationship between $\mathrm{CO}$ and $\mathrm{CO}_{2}$. As mentioned earlier, emission of $\mathrm{CO}_{2}$ is an indication of complete combustion, while $\mathrm{CO}$ represents incomplete combustion [12]. It is worth noting that $\mathrm{SGB}$ and its blends promote complete combustion by producing more $\mathrm{CO}_{2}$ than $\mathrm{CO}$ compared to FGB and its blends. Meanwhile, SGB80 has the lowest CO emission, followed by SGB50. Furthermore, the combustion efficacy that is obtained through calculation in Figure 6 is also in good agreement with the experimental results, where SGB and its blends have a higher combustion efficacy than FGB.

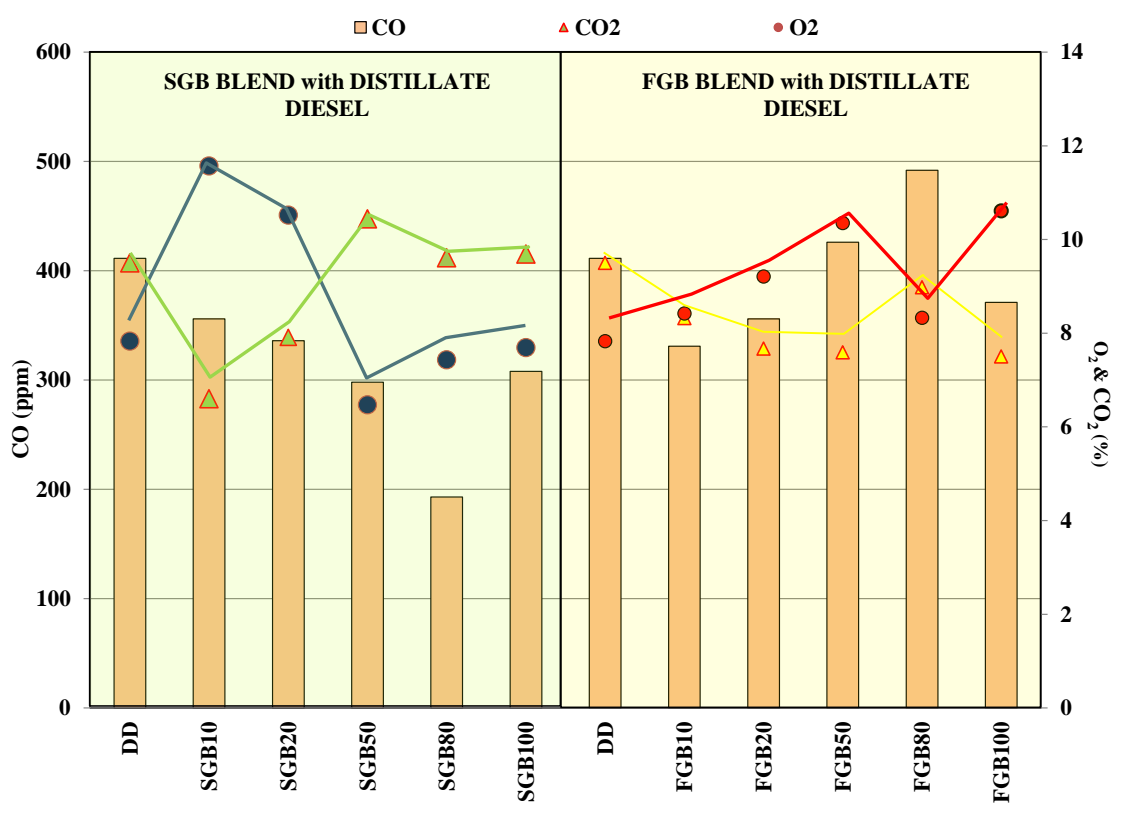

Figure 5. Emissions of different types of fuel.

On the other hand, Figure 7 shows the relationship between $\mathrm{NO}_{\mathrm{x}}$ and flame temperature. The formation of $\mathrm{NO}_{\mathrm{x}}$ in the combustion process is always correlated with adiabatic flame temperature and fuel $\mathrm{NO}_{\mathrm{x}}$. Thermal $\mathrm{NO}_{\mathrm{x}}$ is formed due to the higher combustion temperature in the combustion zone while fuel $\mathrm{NO}_{\mathrm{x}}$ is due to the properties of the fuel or the fatty acids composition of the biodiesel. FGB and SGB have comparable temperature profiles to that of DD in diffusion combustion. Similar results are reported by Glaude, Fournet [13], where the adiabatic flame temperature of the FAMEs is higher than natural gas and close to diesel fuel. This is because biodiesel has a higher oxygen content than fossil diesel, which leads to more complete combustion and hence leads to a greater flame temperature [11]. However, SGB has recorded the highest temperature for SGB50, followed by SGB80. Meanwhile, the flame temperature of FGB and its blends decreased steadily as the percentage of FGB increased in DD. This phenomenon occurs because saturated methyl ester has a higher flame temperature 
than unsaturated fatty acid methyl ester (FAME). Therefore, as the percentage of unsaturated components increased, the temperature decreased for the FGB. Additionally, SGB has a higher calorific value than FGB, thus SGB and its blends produced more thermal energy than FGB. However, Jha, Fernando [11], have reported that increase or decrease of flame temperature is associated with more of the oxygen content of the fuel being used, rather than calorific value. In fact, this statement is in line with the emissions results, where SGB50 and SGB80 have consumed more oxygen than other blends.

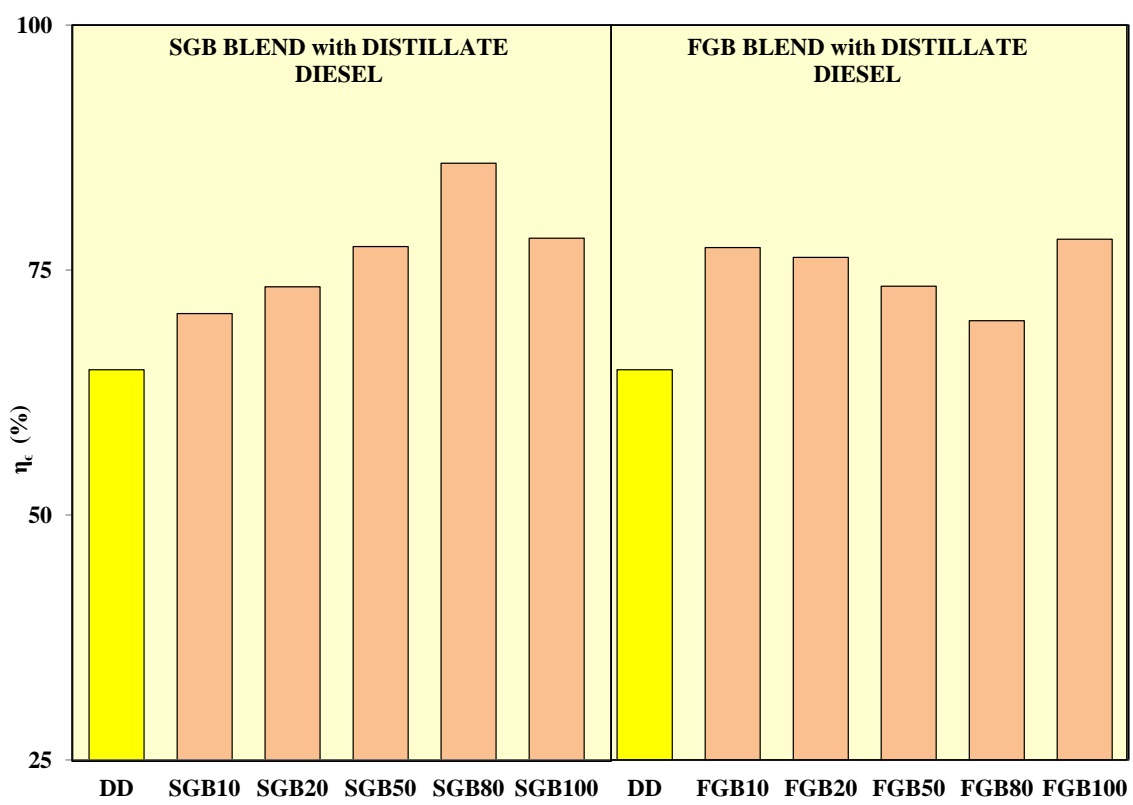

Figure 6. Calculated combustion efficacy.

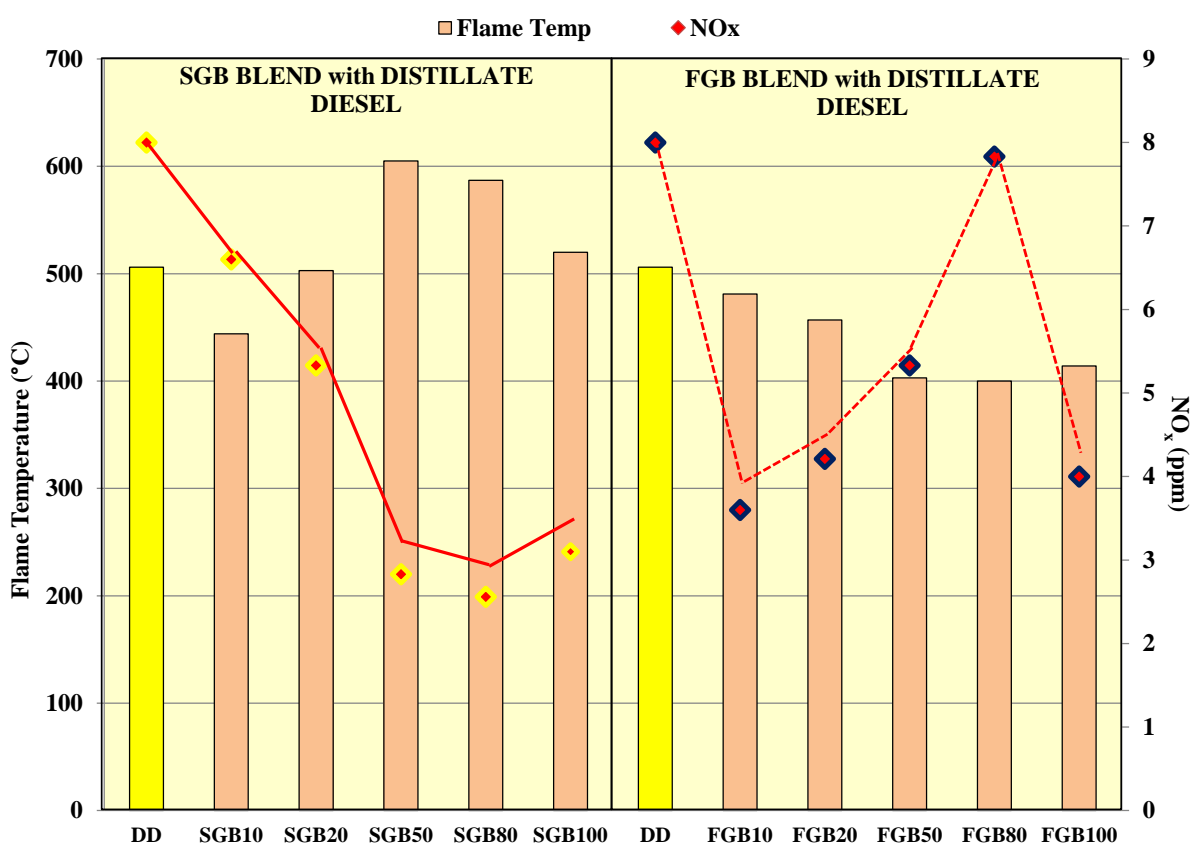

Figure 7. Nitrogen oxide versus temperature. 
Finally, the emission of $\mathrm{NO}_{\mathrm{x}}$ for both $\mathrm{SGB}$ and FGB has decreased compared to DD except for FGB80. Although Klassen, Ramotowski [14] have reported that the diffusion mode of operation tends to produce an unacceptable level of $\mathrm{NO}_{\mathrm{x}}$ emissions compared to premixed combustion, in this work the emission of $\mathrm{NO}_{\mathrm{x}}$ increased slowly as the blend percentage of FGB increased in the DD. On the other hand, although SGB has a higher flame temperature than FGB, the emission of $\mathrm{NO}_{\mathrm{x}}$ is still lower compared to FGB. In this case, the influence of fatty acids composition has shown a stronger effect than flame temperature. As earlier works have reported $[15,16]$, biodiesel with higher unsaturation compounds will generate more $\mathrm{NO}_{\mathrm{x}}$. Nevertheless, Panchasara, Simmons [17] claimed that $\mathrm{NO}_{\mathrm{x}}$ is formed mainly by the thermal mechanism and that fuel chemistry has a negligible effect on $\mathrm{NO}_{\mathrm{x}}$ emission. However, the experiment was performed with an air-assisted injector which is significantly different from the current work. Furthermore, saturate components like methyl palmitate and methyl stearate also have a greater tendency to produce $\mathrm{NO}_{\mathrm{x}}$ than unsaturated components [11]. Therefore, an accurate knowledge of the influence of molecular structure and FAMEs composition on fuel properties enables us to produce optimal quality fuel in terms of performance and emissions. The current work found that SGB has better combustion characteristics than FGB while a detailed combustion study and FAMEs analysis is suggested to understand and elucidate the effects of FAMEs on $\mathrm{NO}_{\mathrm{x}}$ behaviour.

\section{CONCLUSIONS}

The preliminary investigation in a diffusion burner has revealed that SGB has better combustion characteristics than DD and FGB in terms of burning rate, flame length and emission. SGB50 has shown promising results compared to other blends except for flame length. However, the longer flame length may not suitable for microturbine applications due its compact combustor design but can be considered for gas turbine applications. Even though SGB80 shows a comparable performance to SGB50 in terms of emission and combustion efficacy, the flame length of SGB80 is shorter than both DD and SGB50. Furthermore, this work has indicated the effects of improved biodiesel properties on combustion and emission. Although this work differs from real operating conditions, the insights obtained from this study, coupled with further investigation in future, will be helpful to further improve the characteristics of SGB for gas turbine applications.

\section{ACKNOWLEDGEMENTS}

We would like to thank TNBR and Tenaga Nasional Berhad for funding this research through its dedicated renewable energy fund and also rendering their laboratory services to perform physical properties of SGB. We also would like thank UNITEN R\&D Sdn Bhd for their support to manage the funding of this study. Also thanks to participation of biodiesel team members especially Mr. Mohammad Khairzan Idlan bin Ramli who has helped perform gas chromatography analysis at UNITEN GC Laboratory. A special dedication to co-author Mr.Kantharrajan Sandaram who have contributed significantly to perform experiments and analysis for this paper formulation. Sadly he passed away due to road accident recently at the time of the paper accepted in March 2013. 


\section{REFERENCES}

[1] Santos MAnRdNaECd. Biofuel and gas turbine engines, advances in gas turbine technology. Advances in gas turbine technology. Brazil: InTech; 2011.

[2] Schornick JF, Farr RT, DiCampli JK. Liquid biofuels in the aeroderivative gas turbine. General Electric Report, Houston, Texas, USA; 2010.

[3] Prussi M, Chiaramonti D, Riccio G, Martelli F, Pari L. Straight vegetable oil use in Micro-Gas Turbines: System adaptation and testing. Applied Energy. 2012;89:287-95.

[4] Allen CAW, Watts KC, Ackman RG, Pegg MJ. Predicting the viscosity of biodiesel fuels from their fatty acid ester composition. Fuel. 1999;78:1319-26.

[5] Lin Y-S, Lin H-P. Study on the spray characteristics of methyl esters from waste cooking oil at elevated temperature. Renewable Energy. 2010;35:1900-7.

[6] Gopinathan M, Kumaran P, Shihabudin M, Saifudin N. Preliminary property evaluation of second generation biodiesel for gas turbine application. SCoRed University Tenaga Nasional: University Tenaga Nasional; 2010.

[7] Kumaran P, Gopinathan M, Razali N, Kuperjans I, Hariffin B, Hamdan H. Preliminary Evaluation of Atomization Characteristics of Improved Biodiesel for Gas Turbine Application. IOP Conference Series: Earth and Environmental Science: IOP Publishing; 2013. p. 012014.

[8] Gupta KK, Rehman A, Sarviya RM. Bio-fuels for the gas turbine: A review. Renewable and Sustainable Energy Reviews. 2010;14:2946-55.

[9] Tan Ee Sann. Student assignment : performance and emission study of waste cooking oil biodiesel and distillate blends in microturbine application. Putrajaya: Universiti Tenaga Nasional; 2008.

[10] Ramasamy D, Aik Soon K, Walker-Gitano Briggs H, Zainal ZA. Variation of airflow pattern through dissimilar valve lift in a spark ignition engine. Journal of the Chinese Institute of Engineers, Transactions of the Chinese Institute of Engineers,Series A/Chung-kuo Kung Ch'eng Hsuch K'an. 2013;36:1083-96.

[11] Jha SK, Fernando S, To SDF. Flame temperature analysis of biodiesel blends and components. Fuel. 2008;87:1982-8.

[12] Shehata M. Emissions and wall temperatures for lean prevaporized premixed gas turbine combustor. Fuel. 2009;88:446-55.

[13] Glaude P-A, Fournet R, Bounaceur R, Molière M. Adiabatic flame temperature from biofuels and fossil fuels and derived effect on NOx emissions. Fuel Processing Technology. 2010;91:229-35.

[14] Klassen M, Ramotowski M, Eskin L, Roby R. Clean Combustion of liquid biofuels in gas turbines for renewable power generation. American institute of chemical engineers, LPP Combustion LLC, San Antonio. 2010:1-6.

[15] Knothe G. Dependence of biodiesel fuel properties on the structure of fatty acid alkyl esters. Fuel processing technology. 2005;86:1059-70.

[16] Refaat AA. Correlation between the chemical structure of biodiesel and its physical properties. International Journal of Environmental Science \& Technology. 2009;6:677-94.

[17] Panchasara HV, Simmons BM, Agrawal AK, Spear SK, Daly DT. Combustion performance of biodiesel and diesel-vegetable oil blends in a simulated gas turbine burner. ASME Turbo Expo 2008: Power for Land, Sea, and Air. 2009;131:031503. 